\title{
STIMULASI PERKEMBANGAN BAHASA ANAK USIA DINI MELALUI LAGU KREASI MINANGKABAU PADA ANAK USIA DINI
}

\author{
Vivi Anggraini ${ }^{1}$, Yulsyofriend $^{2}$, Indra Yeni $^{3}$, \\ Universitas Negeri Padang \\ Email: vivianggraini887@gmail.com, yulsyofriend@fip.unp.ac.id, \\ indrayeni.30031971@gmail.com
}

\begin{abstract}
Abstrak : Perkembangan bahasa sangatlah penting dikembangkan karena bahasa alat penghubung atau komunikasi antara anggota masyarakat yang terdiri dari individu-individu yang menyatakan pikiran, perasaan, dan keiinginannya. Berbahasa berarti menggunakan bahasa berdasarkan pengetahuan individu tentang adat dan sopan santun. Pada tahapan perkembangan bahasa anak usia dini diawali dengan proses mendengar atau menyimak. Dengan mengajak anak bernyanyi lagu minangkabau bersama, kita memberi anak pengalaman yang berharga lagi menyenangkan, yang dilakukan bersama-sama. Adapun perolehan bernyanyi yang diharapkan, adalah agar anak: (1) mendengar dan menikmati lagu; (2) mengalami rasa senang bernyanyi bersama; (3) mengungkapkan pikiran, perasaan, dan suasana hatinya; (4) merasa senang bernyanyi, dan anak dapat belajar bagaimana mengendalikan suara; (5) menambah perbendaharaan kosa-kata melalui lagu.

Kata kunci: Perkembangan Bahasa, Lagu Kreasi Minangkabau, Anak Usia Dini.
\end{abstract}

Abstrak :Language development is very important to be developed because of the language of the interface or communication between members of the community consisting of individuals who express their thoughts, feelings, and desires. Speaking means using language based on individual knowledge about customs and manners. In the early childhood language development stage begins with the process of hearing or listening. By inviting children to sing Minangkabau songs together, we give children a valuable and enjoyable experience, which is done together. As for the expected singing, is for children: (1) to hear and enjoy the song; (2) experience the feeling of singing together; (3) expressing thoughts, feelings, and moods; (4) feel like singing, and children can learn how to control sound; (5) adding vocabulary vocabulary through songs.

Keywords: Language Development, Minangkabau Creation Song, Early Childhood.

\section{PENDAHULUAN}

Pendidikan Anak Usia Dini

(PAUD) diselenggarakan dengan tujuan untuk memfasilitasi pertumbuhan dan perkembangan anak secara menyeluruh. PAUD memberikan kesempatan kepada anak untuk mengembangkan kepribadian dan potensi secara maksimal. Oleh karena itu, lembaga PAUD menyediakan berbagai kegiatan yang dapat mengembangkan berbagai aspek perkembangan seperti kognitif, bahasa, sosial, emosi, fisik dan motorik. 
Berdasarkan peraturan pemerintah tersebut, diperlukan kesadaran serta peran dari masyarakat akan pentingnya PAUD sebagai peletak dasar dan persiapan sebelum anak melanjutkan sekolah dasar. Usia Dini merupakan masa penting bagi anak untuk mendapatkan pendidikan. Agar anak mampu menunjukkan sikap yang baik dan diinginkan oleh orang tua, pendidik, teman dan masyarakat, maka anak memerlukan satu hal yang paling penting yaitu kemampuan untuk mengungkapkan perasaan, ide, dan pikiran melalui berbicara.

Bahasa merupakan salah satu parameter dalam perkembangan anak. Kemampuan bahasa melibatkan perkembangan kognitif, sensorimotor, psikologis, emosi dan lingkungan sekitar anak. Kemampuan bahasa pada umumnya dapat dibedakan atas kemampuan reseptif (mendengar dan memahami) dan kemampuan ekspresif (berbicara). Kemampuan bicara lebih dapat dinilai dari kemampuan lainnya sehingga pembahasan mengenai kemampuan bahasa lebih sering dikaitkan dengan kemampuan berbicara.

Kemahiran dalam bahasa pada anak dipengaruhi oleh faktor intrinsik yang berasal dari anak dan faktor ekstrinsik yang berasal dari lingkungan. Faktor intrinsik adalah kondisi pembawaan anak sejak lahir termasuk fisiologi dari organ yang terlibat dalam kemampuan bahasa dan berbicara. Sementara itu, faktor ekstrinsik menjelma berupa stimulus yang ada di sekeliling anak terutama perkataan yang didengar atau ditujukan kepada si anak. Untuk itu pentingnya stimulasi yang tepat terhadap perkembangan bahasa anak seperti penggunaan lagu daerah. Lagu daerah adalah lagu yang berasal dari kebudayaan, adat, istiadat dari suatu daerah. Dalam penerapan stimulasi bagi anak hendaknya yang paling dekat dengan lingkungan anak, sehingga lagu daerah adalah salah satu alternatif untuk mengembangkan kemampuan bahasa anak usia dini. Lagu kreasi Minangkabau merupakan lagu yang dibuat dan dikreasikan menggunakan bahasa minangkabau. Lagu daerah dapat diaplikasikan kepada anak usia dini adalah lagu yang disesuaikan dengan karakteristik anak, kebutuhan dan perkembangan anak. Sehingga tujuan utama perkembangan bahasa anak dapat berkembang secara optimal.

\section{PERKEMBANGAN BAHASA} Pengertian Perkembangan Bahasa Anak Usia Dini

Bahasa adalah alat penghubung atau komunikasi antara anggota masyarakat yang terdiri dari individu-individu yang menyatakan pikiran, perasaan dan keinginannya. Bahasa diartikan sebagai sistem simbol yang teratur untuk mentransper berbagai ide maupun informasi yang terdiri dari simbolsimbol visual maupun verbal. Bahasa 
adalah suatu sistem simbol untuk berkomunikasi dengan orang lain.

$$
\text { Hurlock }
$$

mengungkapkan bahasa adalah ucapan pikiran dan perasaan seseorang yang teratur yang digunakan sebagai alat komunikasi antar anggota masyarakat yang terdiri dari menyimak, berbicara, membaca dan menulis. Bahasa merupakan suatu sistem komunikasi yang terintegrasi, mencakup bahasa ujaran, membaca dan menulis hal ini di ungkapkan Abdurrahman (2003:183).

Dari uraian di atas dapat disimpulkan bahwa bahasa merupakan suatu tata bahasa yang digunakan individu untuk berkomunikasi yang terdiri dari menyimak, berbicara, menulis dan membaca. Oleh sebab itu kita semua harus menyadari pentingnya bahasa dalam kehidupan karena dengan bahasa kita dapat berkomunikasi dengan orang lain menyampaikan maksud, pikiran, dan gagasan yang akan bisa dipahami oleh generasi ratusan tahun mendatang.

Antara bahasa dan pengekspresian bahasa adalah dua hal yang berbeda. Bahasa ada di dalam otak dan ia akan tetap ada walaupun diekspresikan ataupun tidak. Seseorang yang tidak bisa bicara (bisu) bukan berarti tidak memiliki bahasa. Ia tetap mengetahui tentang kosa kata bahasa dan dapat menyimpan pengetahuannya dalam bentuk bahasahanya saja cara mengekspresikan bahasanya berbeda dengan orang biasa. Dalam hal ini bahasa adalah suatu simbol-simbol abstrak yang diorganisasikan menurut suatu aturan umum, yang berada di dalam otak manusia.

Sedangkan Morrison (2012: 223-225) menyatakan bahasa adalah keterampilan persiapan yang paling penting. Anak membutuhkan keterampilan bahasa untuk dapat berhasil di sekolah dan dalam hidup. Keterampilan bahasa yang meliputi:

\section{Tabel 1. Empat Aspek}

Keterampilan Bahasa

\begin{tabular}{|c|c|c|}
\hline Ciri-ciri & Lisan & Tulisan \\
\hline Reseptif & $\begin{array}{c}\text { Mendengarka } \\
\mathrm{n}\end{array}$ & $\begin{array}{c}\text { Membac } \\
\mathrm{a}\end{array}$ \\
\hline $\begin{array}{c}\text { Ekspresi } \\
\mathbf{f}\end{array}$ & Berbicara & Menulis \\
\hline
\end{tabular}

Dalam memperoleh kemampuan berbahasa biasanya kita melalui suatu hubungan urutan yang teratur: mula-mula, pada masa kecil, kita belajar menyimak/mendengarkan bahasa, kemudian berbicara, membaca, dan menulis. Dengan demikian, rangkaian pemerolehan keterampilan berbahasa yaitu keterampilan menyimak, berbicara, membaca, kemudian menulis. Keterampilan menyimak dan berbicara kita pelajari sebelum memasuki sekolah, sedangkan keterampilan membaca dan menulis pada umumnya dipelajari di sekolah. Keempat aspek keterampilan bahasa berhubungan satu sama lain. 
a. Karakteristik Kemampuan

Mari kita lihat urutan dalam perkembangan bahasa menuru Papalia (2012:161) dan pada beberapa karakteristik perkembangan bahasa awal. Kemudian kita akan mempertimbangkan bagaimana bayi belajar bahasa, bagaimana pertumbuhan otak terkait dengan perkembangan bahasa, dan bagaimana peran serta orang tua dan pengasuh.

Tabel 2. Pencapaian bahasa Dari Kelahiran Hingga 3 Tahun

\begin{tabular}{|c|c|}
\hline \multicolumn{2}{|c|}{$\begin{array}{l}\text { Pencapaian bahasa Dari } \\
\text { Kelahiran Hingga } 3 \text { Tahun }\end{array}$} \\
\hline $\begin{array}{l}\text { Usia / } \\
\text { bulan }\end{array}$ & Perkembangan \\
\hline Lahir & $\begin{array}{l}\text { Dapat menangis, dan } \\
\text { merespon suara. }\end{array}$ \\
\hline $\begin{array}{l}11 / 2 \text { to } \\
3^{4}\end{array}$ & Bergumam dan tertawa \\
\hline 3 & $\begin{array}{l}\text { Bermain dengan ucapan } \\
\text { suara }\end{array}$ \\
\hline 5 to 6 & $\begin{array}{l}\text { Mengakui pola suara } \\
\text { dan sering mendengar }\end{array}$ \\
\hline 6 to 7 & $\begin{array}{l}\text { Menggunakan semua } \\
\text { fonem dari bahasa asli. }\end{array}$ \\
\hline $\begin{array}{ll}6 & \text { to } \\
10 & \\
\end{array}$ & $\begin{array}{l}\text { Mengoceh konsonan } \\
\text { dan vokal. }\end{array}$ \\
\hline 9 & $\begin{array}{ll}\text { Menggunakan } & \text { isyarat } \\
\text { untuk berkomunikasi } \\
\text { dan } & \text { memainkan } \\
\text { permainan gesture }\end{array}$ \\
\hline $\begin{array}{ll}9 & \text { to } \\
10 & \end{array}$ & Sengaja meniru suara \\
\hline $\begin{array}{ll}9 & \text { to } \\
12 & \end{array}$ & $\begin{array}{l}\text { Menunjukkan beberapa } \\
\text { gerakan }\end{array}$ \\
\hline $\begin{array}{l}10 \text { to } \\
12\end{array}$ & $\begin{array}{l}\text { Tidak lagi dapat } \\
\text { membedakan suara dan } \\
\text { tidak dalam bahasa } \\
\text { sendiri }\end{array}$ \\
\hline 10 & Kata kata pertama \\
\hline
\end{tabular}

\begin{tabular}{|c|c|}
\hline 14 & \\
\hline $\begin{array}{ll}10 & \text { to } \\
18 & \end{array}$ & $\begin{array}{l}\text { Mengatakan kata-kata } \\
\text { tunggal }\end{array}$ \\
\hline $\begin{array}{ll}12 & \text { to } \\
13 & \end{array}$ & $\begin{array}{l}\text { Memahami fungsi } \\
\text { simbolis penamaan; } \\
\text { tumbuh kosakata pasif. }\end{array}$ \\
\hline 13 & $\begin{array}{l}\text { Menggunakan gerakan } \\
\text { lebih rumit }\end{array}$ \\
\hline 14 & $\begin{array}{l}\text { Menggunakan isyarat } \\
\text { simbolis }\end{array}$ \\
\hline $\begin{array}{ll}16 & \text { to } \\
24 & \end{array}$ & $\begin{array}{l}\text { Belajar banyak kata } \\
\text { baru, memperluas } \\
\text { kosakata ekspresif dari } \\
\text { sekitar } 50 \text { kata-kata } \\
\text { menjadi sebanyak } 400 \\
\text { kata-kata; menggunakan } \\
\text { kata kerja dan kata sifat. }\end{array}$ \\
\hline $\begin{array}{ll}18 & \text { to } \\
24 & \end{array}$ & $\begin{array}{l}\text { Mengatakan kalimat } \\
\text { pertama (2 kata) }\end{array}$ \\
\hline 20 & $\begin{array}{l}\text { Menggunakan gerakan } \\
\text { yang lebih sedikit; nama } \\
\text { lebih banyak hal }\end{array}$ \\
\hline $\begin{array}{ll}20 & \text { to } \\
22 & \end{array}$ & Memiliki pemahaman \\
\hline 24 & $\begin{array}{l}\text { Menggunakan banyak } \\
\text { frase dua kata; tidak lagi } \\
\text { mengoceh; ingin bicara }\end{array}$ \\
\hline 30 & $\begin{array}{l}\text { Belajar kata-kata baru } \\
\text { hampir setiap hari; } \\
\text { bicara dalam kombinasi } \\
\text { dari tiga atau lebih kata- } \\
\text { kata; membuat } \\
\text { kesalahan tata bahasa. }\end{array}$ \\
\hline 36 & $\begin{array}{lr}\text { Mengatakan } & \text { hingga } \\
1000 \text { kata, } 80 \text { persen } \\
\text { dimengerti; } & \text { membuat } \\
\text { beberapa } & \text { kesalahan } \\
\text { dalam sintaks. } & \end{array}$ \\
\hline
\end{tabular}

Tabel 3. Pencapaian Perkembangan Komunikasi Anak Usia 1-3 Tahun

\begin{tabular}{|c|c|}
\hline Usia & $\begin{array}{c}\text { Pencapaian } \\
\text { Perkembangan }\end{array}$ \\
\hline & \\
\hline
\end{tabular}




\begin{tabular}{|c|c|}
\hline $\begin{array}{l}\text { Pencapa } \\
\text { ian 13- } \\
18 \\
\text { Bulan }\end{array}$ & $\begin{array}{l}\text { Komunikasi }(15 \\
\text { bulan): } \\
\text { - Memahami } 50 \\
\text { kata } \\
\text { - Dapat } \\
\text { menggunakan } \\
\text { 5-10 kata } \\
\text { - Menggabungk } \\
\text { an suara dan } \\
\text { gerak tubuh } \\
\text { - Meniru kata- } \\
\text { kata sederhana } \\
\text { dan tindakan } \\
\text { - Secara } \\
\text { konsisten } \\
\text { mengikuti } \\
\text { petunjuk } \\
\text { sederhana } \\
\text { - Menunjukkan } \\
\text { minat dalam } \\
\text { gambar } \\
\text { - Dapat } \\
\text { mengidentifika } \\
\text { si 1-2 nama } \\
\text { bagian tubuh }\end{array}$ \\
\hline $\begin{array}{l}\text { Pencapa } \\
\text { ian } 19 \text { - } \\
24 \\
\text { Bulan }\end{array}$ & $\begin{array}{l}\text { Komunikasi (usia } \\
21 \text { Bulan): } \\
\text { - Menggunakan } \\
\text { setidaknya } 50 \\
\text { kata } \\
\text { - Memahami } \\
\text { kata-kata baru } \\
\text { dengan cepat } \\
\text { - Secara } \\
\text { konsisten } \\
\text { meniru kata } \\
\text { baru } \\
\text { - Nama objek } \\
\text { dan gambar } \\
\text { - Memahami } \\
\text { kata ganti } \\
\text { sederhana } \\
\text { (saya, Anda, } \\
\text { saya) } \\
\text { Mengidentifik } \\
\end{array}$ \\
\hline
\end{tabular}

\begin{tabular}{|c|c|}
\hline & $\begin{array}{l}\text { asi 3-5 bagian } \\
\text { tubuh ketika } \\
\text { bernama } \\
\text { (usia } 24 \text { bulan): } \\
\text { - Menggunakan } \\
\text { gerak tubuh } \\
\text { dan kata-kata } \\
\text { saat bermain } \\
\text { pura-pura } \\
\text { - Awal } \\
\text { menggunakan } \\
2 \text { frase kata } \\
\text { - Menggunakan } \\
\text { kata ganti } \\
\text { sederhana } \\
\text { (saya, Anda, } \\
\text { saya) } \\
\text { - Memahami } \\
\text { kata-kata } \\
\text { tindakan } \\
\text { - Suka } \\
\text { mendengarkan } \\
\text { cerita } \\
\text { - Mengikuti } 2 \\
\text { langkah } \\
\text { petunjuk }\end{array}$ \\
\hline $\begin{array}{l}\text { Pencapa } \\
\text { ian 2-3 } \\
\text { Tahun }\end{array}$ & $\begin{array}{l}\text { Komunikasi (Usia } \\
30 \text { bulan): } \\
\text { - Secara } \\
\text { konsisten } \\
\text { menggunakan } \\
\text { 2-3 frase kata } \\
\text { - Menggunakan } \\
\text { "di" dan } \\
\text { "pada" } \\
\text { - Setidaknya } \\
\text { 50\% dari } \\
\text { pidato } \\
\text { dipahami oleh } \\
\text { pengasuh } \\
\text { - Mengikuti } 2 \\
\text { langkah } \\
\text { petunjuk yang } \\
\text { tidak terkait }\end{array}$ \\
\hline
\end{tabular}




\begin{tabular}{|c|c|}
\hline & $\begin{array}{l}\text { - Memahami } \\
\text { kata benda } \\
\text { dasar dan kata } \\
\text { ganti } \\
\text { - Memahami } \\
\text { "saya" dan } \\
\text { "milikmu" }\end{array}$ \\
\hline 3 tahun & $\begin{array}{l}\text { Usia } 36 \text { bulan: } \\
\text { - } \text { Tanyakan } \\
\text { pertanyaan } \\
\text { "apa" dan "di } \\
\text { mana" } \\
\text { - Menggunakan } \\
\text { bentuk jamak } \\
\text { - Sebagian besar } \\
\text { pidato } \\
\text { dipahami oleh } \\
\text { pengasuh } \\
\text { - Pemahaman } \\
\text { sederhana dari } \\
\text { konsep } \\
\text { termasuk } \\
\text { warna, ruang, } \\
\text { waktu } \\
\text { - Memahami } \\
\text { pertanyaan } \\
\text { "mengapa" } \\
\text { - Memahami } \\
\text { kalimat yang } \\
\text { paling } \\
\text { sederhana }\end{array}$ \\
\hline
\end{tabular}

Anak usia 5-6 tahun mempunyai karakteristik khusus dalam kemampuan bahasa, banyak ditemui anak usia 5-6 tahun belum mampu berbicara dengan lancar. Untuk anak yang memiliki kesempatan di Taman Kanak-kanak perkembangan berbicara berkembang pesat. Diantaranya mampu mengungkapkan kalimat sederhana, beberapa kosa kata yang sering ia dengar, menyimak cerita sederhana dan menceritakan kembali ataupun membuat pertanyaan sederhana dan mengungkapkan pertanyaan.

Anak adalah unik. Beragam kecerdasan yang mampu dikembangkan. Salah satu adalah kecerdasan linguistik, seseorang yang mempunyai kecerdasan linguistik tinggi akan berbahasa lancar, baik dan lengkap.

$$
\text { Suyadi (2009 : 108) }
$$

mengungkapkan kemampuan bahasa anak usia 5-6 tahun meliputi: “(a) mampu berbicara dengan lancar; (b) mampu bertanya lebih banyak dan menjawab lebih kompleks; (c) mampu mengenal bilangan dan berhitung; (d) mampu menulis namanya sendiri; (e) mampu membuat pantun sederhana. Suyadi menjelaskan bahwa kemampuan berbicara anak usia 5-6 tahun telah berada pada tahapan komplek dimana anak sudah mampu berbicara dengan lancar.

Dari beberapa uraian di atas mengenai karakteristik kemampuan bahasa anak usia dini maka dapat disimpulkan, perkembangan bahasa anak disesuaikan dengan usia dimana anak sudah mampu mengoceh, anak sudah mampu untuk melakukan percakapan dengan orang lain, dan menggunakan kosa kata semakin meningkat hingga 2500 kosa kata, sehingga pada masa usia ini anak sudah mampu untuk mulai dapat menjadi pendengar yang baik dan melakukan percakapan dengan teman sebaya.

\section{LAGU}

KREASI MINANGKABAU BAGI ANAK

Dalam mengembangkan pengajaran musik di PAUD, ada dua hal dasar yang perlu diperhatikan oleh seorang pendidik, yaitu dasar kependidikan dan dasar teoritis. Menurut Kamtini dan Tanjung 
(2005: 108-109), beberapa hal yang perlu dipertimbangkan dalam menyediakan bahan lagu atau musik sebagai dasar kependidikan, antara lain: Pertama, aspek psikologis. Isi lagu atau musik benar-benar sesuai dengan jiwa dan alam pikiran anak; Kedua, aspek fisik. Tenaga, kekuatan, kemampuan dan keterampilan anak masih terbatas. Organ-organ tubuh seperti alat-alat pernapasan dan alat-alat suara masih dalam taraf pertumbuhan; Ketiga, aspek sosiologis. Penyediaan musik atau lagu tidak keluar dari lingkungan hidup anak: suka-duka dan pergaulan kanak-kanak seharihari, rasa kasih sayang dan sebagainya; Keempat, aspek paedagogis. Bahan musik yang disediakan dianggap dapat membantu perkembangan, pertumbuhan, kecerdasan dan keterampilan anak dalam segala hal menuju kedewasaan secara wajar; Kelima, aspek didaktis. Melodi harus sederhana. Langkah interval jangan terlalu sukar, sebaiknya jarak nada berdekatan tidak melampaui kuart. Ritme (rhythm) atau irama yang dipakai yang mudah saja, nada-nada yang digunakan cukup sampai nada $1 / 8$.

Selain itu, perlu diketahui, diperhatikan, dan dipertimbangkan karakteristik suara dan musik anak yang sesuai dengan aspek-aspek perkembangannya. Anak usia PAUD belajar berbicara dan bernyanyi dengan cara meniru apa yang mereka dengar dan meresponsnya serta mengekspresikannya dengan cara mereka masing-masing.

Dalam memilih lagu bagi anak usia PAUD, ada beberapa hal yang perlu diperhatikan. Menurut Palmer seperti dikutip Rachmi
(2008: 2.16), lagu yang dipilih untuk anak-anak prasekolah adalah lagu yang : (1) dapat mendorong anak untuk aktif terlibat dalam kegiatan yang diselenggarakan pendidik; (2) berhubungan dengan minat anakanak; (3) berhubungan dengan dunia anak-anak; (4) memiliki melodi yang berisi frase-frase yang diulang-ulang sehingga mudah dipelajari dan diingat oleh anak-anak; (5) menekankan pada unsur-unsur ritmik, irama, dan aliterasi; (6) bila berupa rekaman dari berbagai versi lagu atau musik instrumentalia yang liriknya mudah untuk diganti dengan lirik yang baru ciptaan pendidik dan peserta didik; (7) anak-anak dapat diminta untuk menggantikan namanya sendiri, atau temantemannya, atau saudara-saudaranya bila lagu tersebut menyebutkan nama orang.

Dengan karakteristik seperti itu, dalam memilih lagu untuk anak PAUD pendidik perlu memperhatikan karakteristik suara dan lagu anak usia PAUD. Lagu hendaknya dapat mengembangkan dan meningkatkan pengalaman musikal dan suasana hati anak dengan mengambil tema-tema yang kontras.

Mei-Ying Liao, dkk (2014: 144) mengungkapkan bahwa; Bernyanyi memainkan peran penting untuk pengembangan musik dan pendidikan anak-anak dalam pengalaman taman kanak-kanak mereka pada usia 5-6 tahun. Meskipun guru TK memiliki kemampuan terbatas untuk mengajar musik, menyanyi adalah salah satu kegiatan musik paling dominan yang digunakan di taman kanak-kanak. Lagu dan nyanyian sangat direkomendasikan sebagai bahan dan 
proses belajar di kelas taman kanakkanak. Menyanyi adalah kegiatan yang meningkatkan keterampilan perkembangan.

$$
\text { Derya Arslan (2015: 2) }
$$

menyatakan bahwa: salah satu kegiatan yang dilakukan dalam rangka meningkatkan kesadaran fonologis adalah menyanyikan lagu. Lagu adalah salah satu alat penting yang digunakan dalam pendidikan, terutama dalam pengajaran bahasa. Priska dkk (2013: 2), menyatakan sebagai berikut: Lagu adalah media komunikasi verbal yang memiliki makna. Lagu daerah adalah lagu yang berasal dari kebudayaan, adat, istiadat dari suatu daerah. Dalam penerapan stimulasi bagi anak hendaknya yang paling dekat dengan lingkungan anak, sehingga lagu daerah adalah salah satu alternatif untuk mengembangkan kemampuan bahasa anak usia dini. Lagu kreasi Minangkabau merupakan lagu yang dibuat dan dikreasikan menggunakan bahasa minangkabau. Lagu daerah dapat diaplikasikan kepada anak usia dini adalah lagu yang disesuaikan dengan karakteristik anak, kebutuhan dan perkembangan anak. Sehingga tujuan utama perkembangan bahasa anak dapat berkembang secara optimal

Begitupun dengan proses pembuatan lirik di lagu-lagu Minang. Lagu Minang hanya judul untuk lagu-lagu dari Minangkabau atau Sumatera Barat. Karena pengaruh dialek, lagu-lagu Minangkabau sering disebut sebagai lagu-lagu Minang saja. Dari sini diketahui bahwa sebenarnya lagu Minang adalah sejenis lagu daerah bukan lagu rakyat (folk song). Lagu-lagu daerah mencerminkan norma-norma dan nilai-nilai budaya Minangkabau.

\section{PEMBAHASAN}

Bahasa adalah ekspresi kemampuan manusia yang bersifat innate atau bawaan. Dari pengertian ini dapat disimpulkan bahwa sejak lahir kita telah dilengkapi dengan kapasitas untuk dapat menggunakan bahasa. Kemampuan menggunakan bahasa bersifat instinktif (naluriah), Dari uraian dapat ditarik kesimpulan bahwa bahasa merupakan suatu sistem lambang yang digunakan sebagai alat komunikasi oleh anggota masyarakat yang bersifat manusiawi.

$$
\text { Pada Anak Usia Dini }
$$

Perkembangan Bahasa sangatlah penting dikembangkan karena bahasa alat penghubung atau komunikasi antara anggota masyarakat yang terdiri dari individu-individu yang menyatakan pikiran, perasaan, dan keiinginannya. Berbahasa berarti menggunakan bahasa berdasarkan pengetahuan individu tentang adat dan sopa. Bernyanyi adalah kegiatan musik yang fundamental, karena anak dapat mendengar melalui inderanya sendiri; menyuarakan beragam tinggi nada dan irama dengan suaranya sendiri.

Di taman kanak-kanak, musik adalah salah satu wahana bagi anak untuk belajar mengungkapkan pikiran dan perasaan, baik sebagai perorangan maupun sebagai anggota kelompok. Kegiatan musik yang dilakukannya sendiri atau bersamasama, dapat membantu anak memantapkan emosi, dan menggunakan emosi sebaik-baiknya. Menurut Yeni (2011: 104), kegiatan musik dapat meletakkan dasar bagi perkembangan minat dan bakat musik anak selanjutnya. Perkembangan itu sendiri tidak terlepas dari sejauh mana anak memperoleh pengalaman musik secara langsung. Lagu adalah salah 
satu perwujudan bentuk pernyataan atau pesan yang memiliki daya menggerakkan hati, berwawasan citarasa keindahan, dan cita rasa estetika yang dikomunikasikan. Karena itu, lagu memiliki fungsi sosial. Kekuatan lagu pada fungsi ini dapat kita lihat dibidang pendidikan. Melalui lagu, kita membantu anak menumbuh-kembangkan aspekaspek seperti: intelegensi,sosial, emosi, dan psikomotor. Melalui lagu yang sesuai, anak dapat: (1) menambah perbendaharaan bahasa, berbuat kreatif, berimajinasi (segi intelegensi); (2) bermain bersama, mematuhi aturan permainan, tidak mementingkan diri sendiri (segi sosial); (3) menyalurkan emosi, menimbulkan rasa senang (segi emosi); dan (4) melatih otot badan, mengkoordinasikan gerak tubuh (segi psikomotorik).

Atas dasar itu pula, lagu dikatakan (1) bahasa nada, (2) bahasa emosi, dan (3) bahasa gerak. Bahasa nada, karena lagu dapat didengar, dinyanyikan, dan dikomunikasikan. Bahasa emosi, karena lagu dapat menggugah rasa semangat, kagum, atau haru. Bahasa gerak, karena lagu itu sendiri adalah gerak, tergambar pada birama (ketukan keras-lunak), pada pola irama (panjang pendek bunyi), dan pada melodi (tinggirendah nada), yang dapat memotivasi anak melakukan gerak jasmani. Sehingga lagu mampu mengembangkan bahasa verbal maupun non verbal bagi anak usia dini

Dengan mengajak anak bernyanyi bersama, kita memberi anak pengalaman yang berharga lagi menyenangkan, yang dilakukan bersama-sama. Adapun perolehan bernyanyi yang diharapkan, adalah agar anak: (1) mendengar dan menikmati lagu; (2) mengalami rasa senang bernyanyi bersama; (3) mengungkapkan pikiran, perasaan, dan suasana hatinya; (4) merasa senang bernyanyi, dan anak dapat belajar bagaimana mengendalikan suara; (5) menambah perbendaharaan kosa-kata melaui lagu.

Dalam kreasi Minangkabau lagu bukan hanya menyanyikan lagulagu Minangkabau, tetapi lagu itu menciptakannya menjadi sesuatu yang menarik. Penggunaan musik dan gerak ketukan yang merupakan kesatuan harmonisasi yang indah, yang di dalamnya menyimpan makna dan informasi yang akan disampaikan melalui bahasa Minangkabau. Dengan maksud meningkatkan kemampuan berbicara Minangkabau terus menjadi ciri khas lokal dan masih dilestarikan keberadaannya oleh masyarakat Minangkabau itu sendiri, melalui pembuatan lagu Minangkabau.

Anak bernyanyi menurut cara dan gayanya sendiri, karena ia menyenanginya. Benar, kita dapat menyuruh anak bernyanyi dengan cara lain, yang menurut pendapat kita hasilnya akan lebih baik, umpamanya menyuruh anak melakukan latihan vokal dengan paksa, atau dengan latihan yang melelahkan. Maksudnya agar anak dapat meningkatkan mutu suaranya. Namun cara ini kurang bijak, karena dapat mengurangi rasa senang, rasa gembira anak bernyanyi. Akibatnya, bisa-bisa anak kurang menyukai musik, atau bernyanyi.

Karena bernyanyi memegang peran sangat penting dalam proses pembelajaran di PAUD, maka guru dituntut memiliki kemampuan 
Stimulasi bahasa yang akan diajarkan kepada peserta didik.

\section{SIMPULAN}

Pendidikan anak usia dini merupakan penyedia berbagai kegiatan yang dapat mengembangkan berbagai aspek perkembangan seperti kognitif, bahasa, sosial, emosi, fisik dan motorik. Untuk itu diperlukan kesadaran serta peran dari masyarakat akan pentingnya PAUD sebagai peletak dasar dan persiapan sebelum anak melanjutkan sekolah dasar. Usia Dini merupakan masa penting bagi anak untuk mendapatkan pendidikan. Agar anak mampu menunjukkan sikap yang baik dan diinginkan oleh orang tua, pendidik, teman dan masyarakat, maka anak memerlukan satu hal yang paling penting yaitu kemampuan untuk mengungkapkan perasaan, ide, dan pikiran melalui berbicara.

Perkembangan Bahasa sangatlah penting dikembangkan karena bahasa alat penghubung atau komunikasi antara anggota masyarakat yang terdiri dari individu-individu yang menyatakan pikiran, perasaan, dan keiinginannya. Berbahasa berarti menggunakan bahasa berdasarkan pengetahuan individu tentang adat dan sopan santun. Pada tahapan perkembangan bahasa anak usia dini diawali dengan proses mendengar atau menyimak. Dengan mengajak anak bernyanyi bersama, kita memberi anak pengalaman yang berharga lagi menyenangkan, yang dilakukan bersama-sama. Adapun perolehan bernyanyi yang diharapkan, adalah agar anak: (1) mendengar dan menikmati lagu; (2) mengalami rasa senang bernyanyi bersama; (3) mengungkapkan pikiran, perasaan, dan suasana hatinya; (4) merasa senang bernyanyi, dan anak dapat belajar bagaimana mengendalikan suara; (5) menambah perbendaharaan kosa-kata melaui lagu.

Lagu daerah adalah lagu yang berasal dari kebudayaan, adat, istiadat dari suatu daerah. Dalam penerapan stimulasi bagi anak hendaknya yang paling dekat dengan lingkungan anak, sehingga lagu daerah adalah salah satu alternatif untuk mengembangkan kemampuan bahasa anak usia dini. Lagu kreasi Minangkabau merupakan lagu yang dibuat dan dikreasikan menggunakan bahasa minangkabau. Lagu daerah dapat diaplikasikan kepada anak usia dini adalah lagu yang disesuaikan dengan karakteristik anak, kebutuhan dan perkembangan anak. Sehingga tujuan utama perkembangan bahasa anak dapat berkembang secara optimal.

\section{DAFTAR PUSTAKA}

Arslan, Derya. (2015). "First Grade Teachers Teach Reading With Songs," Journal of Humanities and Social Sciences, Vol. 20, July.

Gaies, Stephen J. (2013). "ESL Teachers' Classroom Speech." Paper presented at the Sixth Annual Conference of the New York State English to Speakers of Other Languages and Bilingual Education Association, Albany, N.Y.

Gina, dkk. (2012). "Penggunaan Kato Nan Ampek Sebagai Komunikasi Nonverbal Dalam Komunikasi Antar Budaya Mahasiswa Minangkabau Perantauan." 
Jurnal Eproc, Vol. 1, September.

Hurlock, Elizabeth B. Perkembangan Anak Edisi Keenam.( Jakarta : Erlangga,1997)h.11

Abdurrahman, Mulyono. (2003). "Pendidikan Bagi Anak Berkesulitan Belajar". Jakarta : Rineka Cipta.

Morrison, George S. (2012). "Dasar-Dasar

Pendidikan Anak Usia

Dini

(PAUD)",

Jakarta:Indeks.

Papalia, Diane E. (2012).

"Perience Human

Development ". Mc Graw

Hill: United States America.

Pathways, "All Developmental Milestones,"

Pathways.Org Online; https://pathways.org/mile stones/ (diakses 20 Maret 2016) Pukul. 21.00

Suyadi. (2009). "Psikologi belajar PAUD”. Jakarta: Pedagogia

Badudu dan Zain. (2007). "Kamus Umum Bahasa Indonesia". Jakarta : Pustaka.

Jamalus. 1998. Pengajaran Musik melalui

Pengalaman Musik. Jakarta:

P2LPTK. Departemen

Pendidikan dan

Kebudayaan.

Kamtini, dan Tanjung, Husni Wardi. 2005. Bermain melalui Gerak dan Lagu di Taman Kanak-Kanak. Jakarta: Departemen Pendidikan Nasional.
Kamien, Roger. 1998. Music an Appreciations. Annotated Instructor's Edition. New York: McGraw-Hill Book Company.

Mahmud, A.T. 1995. Musik dan Anak. Jakarta: Departemen Pendidikan dan Kebudayaan.

Walton, Patrick D. (2014). "Using Singing and Movement to Teach Prereading Skills and Word Reading to Kindergarten Children." $A n$ Exploratory Study, Volume 16, Issue 3, July.

Pekerti, Widia, dkk. 2008. Metode Pengembangan Seni. Jakarta: Universitas Terbuka.

Pilhofer, Michael dan Day, Holly. 2007. Music Theory for Dummies. New Jersey: Wiley Publishing Inc.

Rachmi, Teti, dkk. 2008. Keterampilan Musik dan Tari. Jakarta: Universitas Terbuka.

Sadiman, Arif S., dkk. 1990. Media Pendidikan, Pengertian,

Pengembangan, dan Pemanfaatannya. Jakarta: CV. Rajawali.

Sanaky, Hujair A.H. 2011. Media Pembelajaran. Yogyakarta: Kaukaba Dipantara.

Soedarsono, R.M. (ed). 1992. Pengantar Apresiasi Seni. Jakarta: Balai Pustaka.

Yeni, Indra. 2009.

Pengantar Seni Musik untuk Pendidikan Anak Usia Dini Padang: Sukabina Press. 
Yeni, Indra. 2012. Metodologi Pengembangan Seni Musik Suara. Padang: Jurusan PGPAUD FIP Universitas Negeri Padang.

Yeni, Indra. 2016. Teknik Iringan Lagu Anak Penggunaan Keyboard sebagai Instrumen Ritmis. Jakarta. Prenada Group

Kellough, Richard D. 1996. Understanding Childrens Art. New York: Macmillan Publishing Company.

Wilson, Margaret Berry. 2011. What Every Kindergarten Teacher Needs to Know: About Setting Up and Running at Classroom. Turner Falls, MA: Northeast Foundation for Children. 